\title{
Outcomes of hysterectomy in HIV-seropositive women compared to seronegative women
}

\author{
JENNIFER FRANZ, DENISE J. JAMIESON, HUGH RANDALL, \& CYRIL SPANN \\ Department of Gynecology and Obstetrics, Emory University, Atlanta, Georgia, USA
}

\begin{abstract}
Objective. To compare the postoperative complication rates after hysterectomy between HIV-infected patients and HIVuninfected patients.

Study design. We conducted a retrospective study of 24 human immunodeficiency virus-infected patients who underwent hysterectomy between January 1, 2000 and April 2, 2003 at Grady Memorial Hospital. Postoperative complications rates among HIV-infected women were compared to those rates among HIV-uninfected women. Data were analyzed $t$-tests for continuous variables and chi-squared tests for categorical variables.

Results. The HIV-infected women were more likely to report smoking and recreational drug use. In addition, a higher proportion of the HIV-infected women were co-infected with hepatitis, with more than one-quarter of HIV-infected women being hepatitis B or C seropositive. Although the study was limited due to small sample size, no significant differences in complication rates were found among HIV-infected women compared with uninfected women.

Conclusion. As HIV-infected women are living longer, healthier lives we anticipate that increased numbers of HIV-infected women will be undergoing hysterectomy for benign gynecologic conditions. It will be important, therefore, to carefully document any potential differences in operative risks.
\end{abstract}

Keywords: Hysterectomy, human immunodeficiency virus, postoperative morbidity

\section{Introduction}

Women are increasingly affected by HIV; more than one-fifth of all persons living with AIDS in the United States are women [1]. Since hysterectomy is the one of the most common non-obstetrical major surgical procedures that women undergo, one would expect that a sizeable number of HIV-infected women would undergo hysterectomy. In addition, some conditions that may lead to hysterectomy, such as cervical dysplasia, are more common in HIVinfected women. Therefore, we retrospectively reviewed the clinical experience of HIV-infected women undergoing hysterectomy compared to HIV-uninfected women undergoing hysterectomy.

\section{Methods}

All women who underwent hysterectomy from January 1, 2000 to April 2, 2003 were selected from a surgical database which contains all surgery performed at Grady Memorial Hospital. Among the 745 hysterectomy cases, $27(4 \%)$ women were known to be HIV-infected at the time of their surgery. Three women were excluded who underwent surgery for a malignancy.

For the 24 eligible HIV-infected women, two control groups were established. Both control groups were matched by age ( \pm 8 years), primary indication for surgery (infectious vs. non-infectious), major medical complication (such as poorly controlled diabetes, hypertension), past surgical history (major abdominal surgery, not including cesarean section), and type of procedure performed. In addition to the above factors, the first control group was matched by uterine weight and the second was matched by operating time.

The primary outcome of interest was the complication rate associated with hysterectomy. The complication rate was defined as having one or more of the following complications: postoperative febrile morbidity, wound infection, postoperative urinary tract infection, re-admission to the hospital, reoperation, intra-operative or postoperative blood

Correspondence: Jennifer Franz, 69 Jessie Hill Drive, Atlanta, Georgia 30303, USA. Tel: 404686 1000. E-mail: jfranz01@hotmail.com 
Table I. Characteristics of the 72 women in the study population.

\begin{tabular}{|c|c|c|c|}
\hline & $\begin{array}{c}\text { HIV-infected } \\
N=24\end{array}$ & $\begin{array}{l}\text { HIV-uninfected controls } \\
\text { matched by uterine weight } \\
\qquad N=24\end{array}$ & $\begin{array}{l}\text { HIV-uninfected controls } \\
\text { matched by operating time } \\
\qquad N=24\end{array}$ \\
\hline Age, years $(\text { mean })^{\star}$ & 40.5 & 41.5 & 40.2 \\
\hline Uterine weight, grams (mean) ${ }^{\star}$ & 253 & 231 & 341 \\
\hline Operating time, minutes $(\text { mean })^{\star}$ & 147 & 133 & 146 \\
\hline \multicolumn{4}{|l|}{ Primary indication ${ }^{\star}$} \\
\hline Uterine leiomyomata & $7(29 \%)$ & $12(50 \%)$ & $11(46 \%)$ \\
\hline Cervical dysplasia & $7(29 \%)$ & $1(4 \%)$ & $0(0 \%)$ \\
\hline Pelvic pain & $3(13 \%)$ & $5(21 \%)$ & $8(33 \%)$ \\
\hline Menometorrhagia & $1(4 \%)$ & $2(8.3 \%)$ & \\
\hline Prolapse & $1(4 \%)$ & $1(4 \%)$ & $2(8 \%)$ \\
\hline Pelvic mass & $3(13 \%)$ & $1(4 \%)$ & $0(0 \%)$ \\
\hline Tubo-ovarian abscess & $2(8 \%)$ & $2(8 \%)$ & $2(8 \%)$ \\
\hline \multicolumn{4}{|l|}{ Surgical approach ${ }^{\star}$} \\
\hline Vaginal & $16(67 \%)$ & $16(67 \%)$ & $16(67 \%)$ \\
\hline Abdominal & $8(33 \%)$ & $8(33 \%)$ & $8(33 \%)$ \\
\hline Current tobacco use & $15(63 \%)$ & $7(29 \%)^{\star \star}$ & $8(33 \%)^{\star \star}$ \\
\hline History of drug use & $10(42 \%)$ & $3(13 \%)^{\star \star}$ & $0(0 \%)^{\star \star}$ \\
\hline Hepatitis B seropositivity & $5(21 \%)$ & $1(4 \%)^{\star \star}$ & $1(4 \%)^{\star \star}$ \\
\hline Hepatitis C seropositivity & $6(25 \%)$ & $0(0 \%)^{\star \star}$ & $0(0 \%)^{\star \star}$ \\
\hline Operative/post-operative complication & $9(38 \%)$ & $4(17 \%)$ & $8(33 \%)$ \\
\hline Estimated blood loss, cc (mean) & 460 & 434 & 537 \\
\hline Total length of hospitalization, days (mean) & 6 & 3.8 & 4 \\
\hline Length of post-operative hospitalization, days (mean) & 3.1 & 2.3 & 2.5 \\
\hline
\end{tabular}

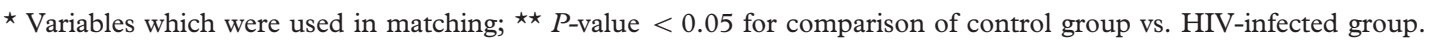

Table II. Characteristics of $24 \mathrm{HIV}$-infected women at time of surgery.

\begin{tabular}{lc}
\hline Characteristic & $N(\%)$ \\
\hline CD4 count (cells $/ \mu \mathrm{l})$ & \\
$\quad<200$ & $3(12 \%)$ \\
$200-350$ & $6(25 \%)$ \\
$350-500$ & $5(21 \%)$ \\
$>500$ & $10(42 \%)$ \\
Plasma viral load (copies/mL) & $5(21 \%)$ \\
$\quad \leqslant 400$ & $5(21 \%)$ \\
$401-2,500$ & $5(21 \%)$ \\
$2,501-5,000$ & $0(0 \%)$ \\
$5,001-10,000$ & $4(17 \%)$ \\
$>10,000$ & $5(21 \%)$ \\
Unknown & \\
Current antiretroviral therapy & $11(46 \%)$ \\
Yes & $13(54 \%)$ \\
No documentation in chart & \\
\hline
\end{tabular}

transfusion, or paralytic ileus. Febrile morbidity was defined as a temperature of greater than $38.0^{\circ} \mathrm{C}$ on two separate occasions eight or more hours apart or one temperature of $38.0^{\circ} \mathrm{C}$ with the use of antibiotics.

The HIV-infected group was compared to each of the control groups in separate comparisons. Differences between means were evaluated using $t$-tests; differences between categorical variables were assessed using chi-squared tests.

\section{Results}

The mean age of women undergoing hysterectomy was approximately 40 years and the mean operating time was approximately $2.5 \mathrm{~h}$. Most surgery was done for non-infectious indications, with the most common indication for surgery being uterine leiomyomas. More HIV-infected women underwent hysterectomy for cervical dysplasia compared with uninfected women. In terms of procedure, 16 women in each group underwent a total vaginal hysterectomy including 2 in each group who underwent laparosopic-assisted vaginal hysterectomy. The remaining women underwent abdominal hysterectomy including one woman undergoing a supracervical hysterectomy (Table I).

Among the $24 \mathrm{HIV}$-infected women, $42 \%$ had a CD 4 count of above 500 cells $/ \mu \mathrm{l}$, and $21 \%$ had a plasma viral load of $<400$ copies $/ \mathrm{mL}$. $46 \%$ of the women had documentation that they were currently taking antiretroviral therapy at the time of the surgery (Table II). When compared with controls, significantly more HIV-infected women reported smoking and recreational drug use. In addition, a higher proportion of HIV-infected women were known to be hepatitis $\mathrm{B}$ and $\mathrm{C}$ seropositive, with more than a quarter of HIV-infected women co-infected with either hepatitis B or C, or both.

Overall, the complication rates among all groups were similar. Among the HIV-infected women, there 
were 12 complications reported among 9 women including febrile morbidity (6), urinary tract infection (1), readmission (3), re-operation (1), and intraoperative blood transfusion (1). Among the 9 $\mathrm{HIV}$-infected women who experienced a postoperative complication, one woman had a CD4 count of less than 200 cells/ $\mu$ l and one woman had a viral load of greater than 10,000 copies/mL. Among the HIVuninfected women matched by uterine weight, there were 4 complications among 4 women including febrile morbidity (2), re-admission (1), and paralytic ileus (1). Among the HIV-uninfected women matched by operating time, there were 8 complications among 8 women including febrile morbidity (1), wound infection (1), re-admission (1), reoperation (1), blood transfusion (3), and paralytic ileus (1). The estimated blood loss was similar in the different groups (approximately $500 \mathrm{cc}$ ) as were the post-operative hospitalization lengths (2-3 days).

\section{Discussion}

The issue about whether or not peri-operative morbidity is greater among HIV-infected women when compared to uninfected women has primarily focused on cesarean section. Much less has been reported about the experience of HIV-infected women undergoing gynecologic surgery and results to date have been conflicting.

In the present study, which included $24 \mathrm{HIV}$ infected women undergoing hysterectomy, we were not able to demonstrate a statistically significant increase in peri-operative morbidity among HIVinfected women when compared to two different control groups. However, we were also not able to definitively demonstrate that there were no differences given our small sample size. Assuming a threefold increase in the overall complication rate, we had only $40 \%$ power to detect a difference.

However, most prior reports have also had extremely limited sample size and were not able to look at hysterectomy separately from other gynecologic procedures. For example, one report by Grubert et al. included 235 surgical procedures, with only 72 being major and including cesarean section, tubal ligation, and oophorectomy in addition to hysterectomy. They reported a higher complica- tion rate in the HIV-infected group [2]. Another report by Sewell et al. reviewed 53 surgical procedures with only 9 hysterectomies; the majority of procedures were minor. They showed no difference in outcome between the HIV-infected women and the uninfected women [3].

An additional limitation of this study is that it was retrospective, and therefore was limited by the information contained in the medical record. Detailed information about the level of training of the primary surgeon was not available since the attending physician was uniformly recorded as the physician of record. In addition, clinical decisions such as use of antibiotics were made based upon clinical judgment rather than prospectively determined by a clinical algorithm. These decisions were likely influenced by the HIV status of the patient, since this information was available to the clinician. Additionally, since there is not universal HIV screening prior to surgery, some women included in the uninfected control group may have been $\mathrm{HIV}$-infected. If some of the women in the control group were HIV-infected, this could have biased our results toward the null, with the control group appearing to having an abnormally elevated complication rate and obscuring any differences between the two groups.

As HIV-infected women are living longer, healthier lives in large part due to advances in antiretroviral therapy, we can anticipate that increased numbers of HIV-infected women will be seeking gynecologic surgery for a variety of benign conditions. It will be important to document whether the risks associated with gynecologic procedures such as hysterectomy are any different among HIVinfected women as compared to uninfected women.

\section{References}

1. Centers for Disease Control and Prevention. HIV/AIDS among US women. Available: http://www.cdc.gov/hiv/pubs/facts/women.htm.

2. Grubert T, Reindell D, Kastner R, et al. Rates of postoperative complications among human immunodeficiency virus-infected women who have undergone obstetric and gynecologic surgical procedures. Clin Infect Dis 2002;34:822-830.

3. Sewell C, Derr R, Anderson J. Operative complications in HIVinfected women undergoing gynecologic surgery. J Reprod Med 2001;46:199-204. 


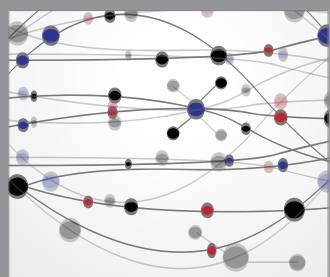

The Scientific World Journal
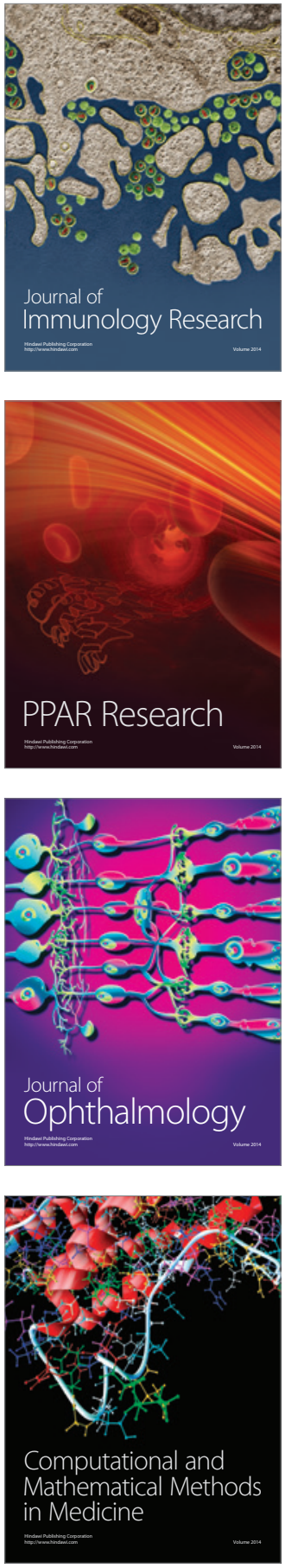

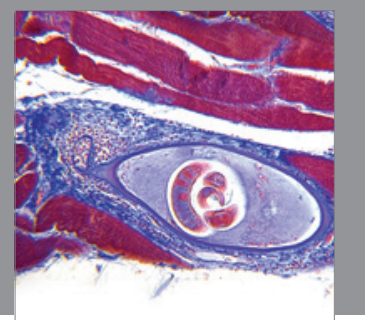

Gastroenterology

Research and Practice
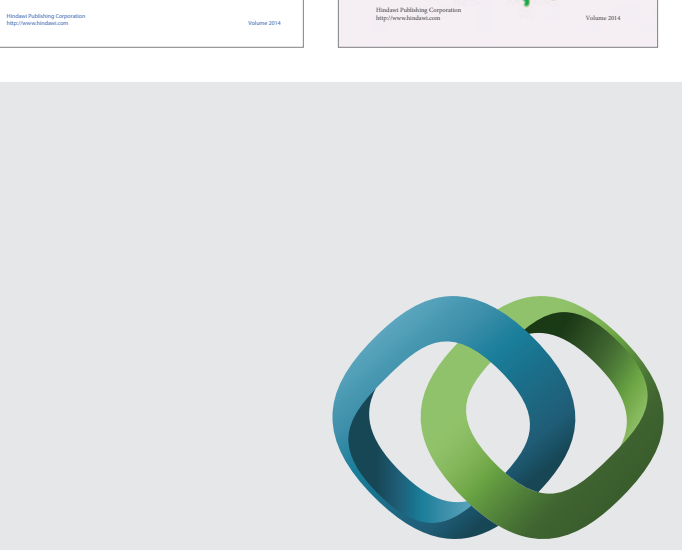

\section{Hindawi}

Submit your manuscripts at

http://www.hindawi.com
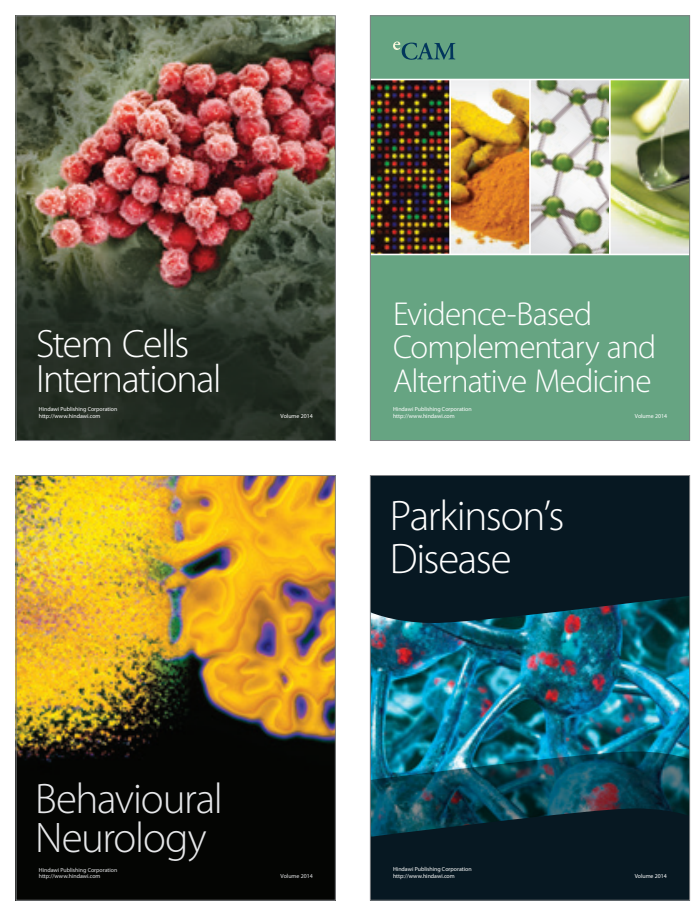

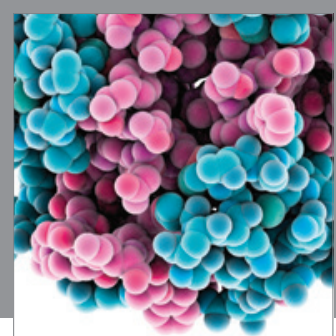

Journal of
Diabetes Research

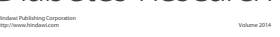

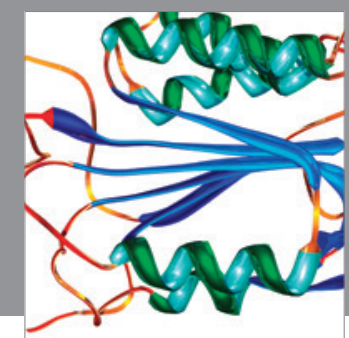

Disease Markers
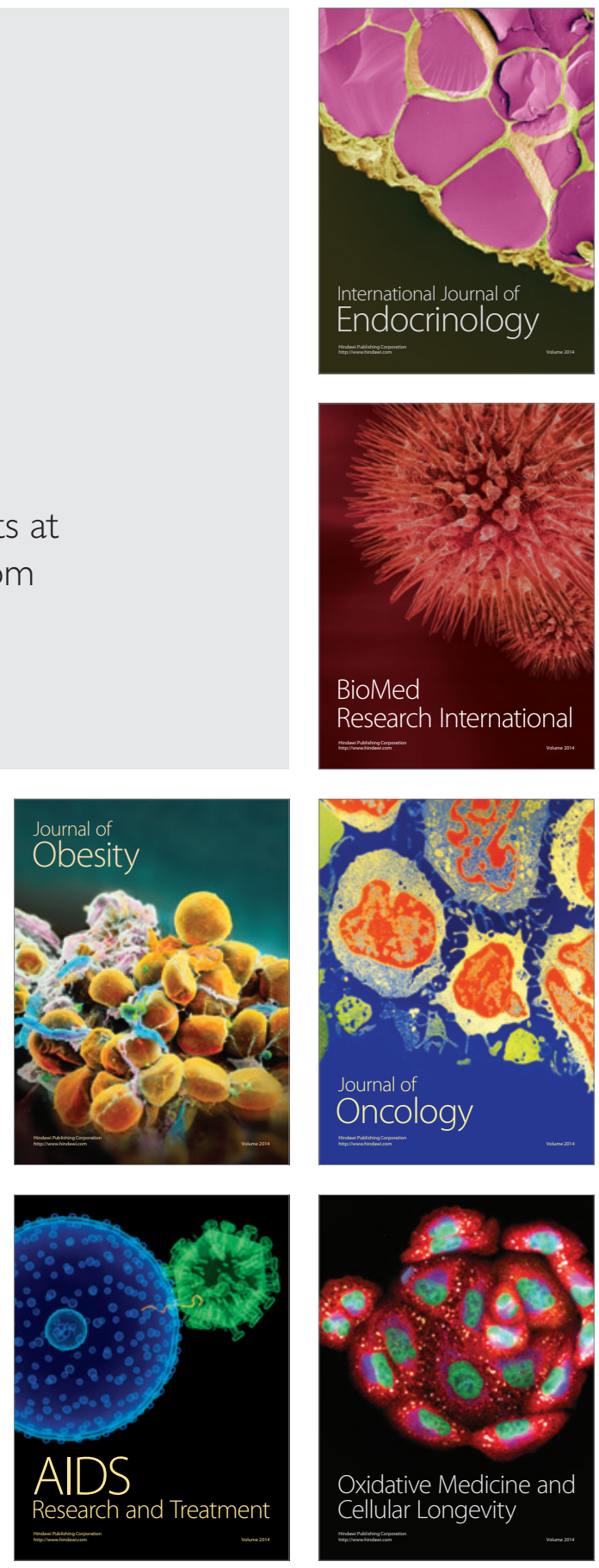